\title{
A conceptual framework for patient-directed knowledge tools to support patient-centred care; Results from an evidence-informed consensus meeting
}

\section{Authors}

Dreesens, Dunja ${ }^{1,2}$, Stiggelbout, Anne ${ }^{3}$, Agoritsas, Thomas ${ }^{4}$, Elwyn, Glyn ${ }^{5}$, Flottorp, Signe ${ }^{6,18}$, Grimshaw, Jeremy ${ }^{7}$, Kremer, Leontien ${ }^{8,9}$, Santesso, Nancy ${ }^{10}$, Stacey, Dawn ${ }^{7,11}$, Treweek, Shaun ${ }^{12}$, Armstrong, Melissa ${ }^{13}$, Gagliardi, Anna ${ }^{14}$, Hill, Sophie ${ }^{15,16}$, Légaré, France ${ }^{17}$, Ryan, Rebecca ${ }^{15,16}$, Vandvik, Per ${ }^{18}$, van der Weijden, Trudy²

\section{Authors' affiliation}

${ }^{1}$ Knowledge Institute of Medical Specialists, Utrecht, The Netherlands

${ }^{2}$ Department of Family Medicine, Maastricht University/School CAPHRI, Maastricht, The Netherlands

${ }^{3}$ Department of Biomedical Data Sciences, Leiden University Medical Centre, Leiden, The Netherlands

${ }^{4}$ Division of General Internal Medicine \& Division of Clinical Epidemiology, University Hospitals of Geneva, Geneva, Switzerland

${ }^{5}$ The Dartmouth Institute for Health Policy and Clinical Practice, Hanover, USA

${ }^{6}$ Division of health services, Norwegian Institute of Public Health, Oslo, Norway

${ }^{7}$ Clinical Epidemiology Program, Ottawa Hospital Research Institute, Ottawa, Canada

${ }^{8}$ Department Pediatrics, University of Amsterdam, Amsterdam, The Netherlands

9 Princess Maxima Centrum for Pediatric Oncology, Utrecht, The Netherlands

${ }^{10}$ Department of Clinical Epidemiology \& Biostatistics, McMaster University, Hamilton, Canada

11 School of Nursing, University of Ottawa, Ottawa, Canada

12 Health Services Research Unit, University of Aberdeen, Aberdeen, UK

${ }^{13}$ Department of Neurology, College of Medicine / University of Florida, Gainesville, USA

${ }^{14}$ University Health Network/Toronto General Hospital Research Institute, Toronto, Canada

${ }^{15}$ Centre for Health Communication and Participation, La Trobe University, Melbourne, Australia

${ }^{16}$ Cochrane Consumers and Communication Group, La Trobe University, Melbourne, Australia

17 Laval University, Québec, Canada

${ }^{18}$ Department of Health Management and Health Economics, University of Oslo, Oslo, Norway

\section{Authors' email addresses}

dunja.dreesens@maastrichtuniversity.nl

A.M.Stiggelbout@lumc.nl

thomas.agoritsas@gmail.com

glynelwyn@gmail.com

signe.flottorp@kunnskapssenteret.no

jgrimshaw@ohri.ca

l.c.kremer@amc.uva.nl

santesna@mcmaster.ca

Dawn.Stacey@uOttawa.ca

streweek@mac.com

Melissa.Armstrong@neurology.ufl.edu/marmstrong@som.umaryland.edu

agagliar@uhnresearch.ca

sophie.hill@latrobe.edu.au

France.Legare@mfa.ulaval.ca

r.ryan@latrobe.edu.au

per.vandvik@gmail.com

trudu.vanderweijden@maastrichtuniversity.nl

\section{Corresponding author:}

Dunja Dreesens

\section{Corresponding author at:}

Maastricht University /School CAPHRI

P.O. Box 616

6200 MD Maastricht

The Netherlands 
+31614344300

dunja.dreesens@maastrichtuniversity.nl

\section{Keywords}

Framework; knowledge; tools; (shared) decision-making; patient education; communication 


\section{Abstract}

Objective

Patient-directed knowledge tools are designed to engage patients in dialogue or deliberation, to support patient decision-making or self-care of chronic conditions. However, an abundance of these exists. The tools themselves and their purposes are not always clearly defined; creating challenges for developers and users (professionals, patients). The study's aim was to develop a conceptual framework of patient-directed knowledge tool types.

\section{Methods}

A face-to-face evidence-informed consensus meeting with 15 international experts. After the meeting, the framework went through two rounds of feedback before informal consensus was reached.

\section{$\underline{\text { Results }}$}

A conceptual framework containing five patient-directed knowledge tool types was developed. The first part of the framework describes the tools' purposes and the second focuses on the tools' core elements.

\section{Conclusion}

The framework provides clarity on which types of patient-directed tools exist, the purposes they serve, and which core elements they prototypically include. It is a working framework and will require further refinement as the area develops, alongside validation with a broader group of stakeholders.

\section{Practice implications}

The framework assists developers and users to know which type a tool belongs, its purpose and core elements, helping them to develop and use the right tool for the right job. 


\subsection{Introduction}

In 1996, Sackett et al described evidence-based medicine as integrating "the best external evidence with individual clinical expertise and patients' choice", and Charles et al tried in 1997 to define shared (treatment) decision-making $(1,2)$. Both heralded the more formal recognition of patient engagement. The WHO defines patient engagement as (the process of building) the capacity of patients, families, carers, as well as healthcare providers, to facilitate and support the active involvement of patients in their own care, in order to enhance safety, quality and people-centeredness of healthcare service delivery (3).

In the past, patient engagement might have been primarily a moral-ethical imperative (4), but this engagement is also associated with numerous beneficial outcomes such as improved knowledge, satisfaction and self-management and reduced decisional conflict (5-9). Moreover, involving the patient is important because physicians may recommend treatments that they would not have chosen themselves (10), and physicians are mostly not adept at predicting what their patients want $(11,12)$. These and other reasons to engage patients in decisions about care have led to the development of a range of knowledge tools $(13,14)$.

Overall, there exists an abundance of tools to engage patients in decision-making and contribute to patient-centred care. Examples of knowledge tools are clinical practice guidelines (CPG), protocols, patient decision aids (PDAs) and patient education materials (15-17). Knowledge tools distil and synthesize the highest quality knowledge and research (18). Patientdirected knowledge tools are aimed directly at the patient (family members and carers), with the goal to engage patients in dialogue or deliberation during a clinical encounter, or to support and/or improve patient decision-making which may or may not take place during a clinical encounter (13). The ultimate goal is to contribute to safer and higher quality healthcare (delivery). However, these types of tools are frequently ill defined (16, 19, 20). Moreover, lack of clarity on development, content, and purpose has likely contributed to poor uptake (21-24).

Several streams of work have contributed to the development of this area. These include development of specific quality criteria for certain tools (such as PDAs, leading to IPDAS, the International Patient Decision Aid Standards) (25-28) as well as frameworks and taxonomies on patient involvement. The purpose of IPDAS is to enhance the quality and effectiveness of patient decision aids by establishing a shared evidence-informed framework (29-31). IPDAS does not consider other patient-directed knowledge tools. Several frameworks related to decision support tools have been developed (32). O'Connor et al developed a decision support framework to develop a specific P.DA, concentrating on determinants of decisions leading to the Ottawa Decision Support Framework $(33,34)$. Another example is a taxonomy of outcomes developed by the Cochrane Consumers \& Communication Group (CCCG) which can be used by researchers and others to conceptually map the range of outcomes, at different levels of health care, that might be relevant when assessing different forms of communication (such as shared decision making) (35).

Existing frameworks tend to focus on PDAs, and the CCCG taxonomy has a far broader scope than just patient-directed knowledge tools. The aim of our study was therefore, building on 
existing work, to develop a conceptual framework of patient-directed knowledge tools (36). Our objective was to create a framework that would identify existing patient-directed tool types, allows organization of these types of tools by their purpose(s) and describes their core elements. The framework is intended primarily for tool developers, and possibly also for those who commission the development of tools, healthcare professionals and policy makers. It should help developers to identify where there is a gap or need for a tool to be developed, and how such a tool may best make information, knowledge and decision support available to patients (37).

\subsection{Methods}

We used a two-day consensus meeting with international experts. We are not aware of standards for reporting a consensus-based meeting. Instead, we followed the Standards for Reporting Qualitative Research (SRQR) as closely as possible, when writing the manuscript (38).

To arrive at a conceptual framework of patient-directed knowledge tool types to engage patients and support patient decision making within a short time frame, the initiators (TVDW, DD) and chair (JG) decided that a two-day, face-to-face meeting with experts was the most optimal design. We followed a consensus-based process based on a written meeting protocol (see annex A) (39-41). The meeting was audio-recorded, DD took. JG and TVDW made field notes. The meeting took place in February 2016, in Leiden, the Netherlands.

The participants were purposefully sampled from the Guideline International Network (GIN), International Shared Decision Making network (ISDM) and the professional networks of the initiators. The participants worked in different domains of knowledge (transfer), implementation and decision support, e.g. as tool developers, implementers or implementation researchers, decision making researchers, or practitioners. The aim was to have representation from a range of countries, individuals with various professional backgrounds, and patients (see annex B). There were two groups of participants; those who participated face-to-face in the group meeting and those who joined remotely for the conference call with the large group, or via e-mail.

During the preparatory phase the participants received a list with relevant literature (see annex C). This list included participants' key articles - suggested by TVDW - and its aim was to achieve a common ground between the participants. They also received a list with possible knowledge tool types to be discussed (see annex D). The list was the result of a scoping review undertaken by initiator DD. The meeting protocol was also shared with the participants in this phase (see annex A) (42). The experts were asked to add missing literature, review the proposed tools and comment on the protocol. If the experts had queries on the provided tools, DD and TVDW provided information to clarify these issues, copying all participants.

The meeting consisted of nine steps (see table 1). In step 1, the face-to-face participant group discussed and came to agreement on the scope of the meeting, and the intended final product(s). In step 2, they discussed the list with tool types (annex D) to ensure that all 
participants present in the face-to-face meeting were familiar with the tools and their definitions, and, if not, described the tool, and verified that the list was complete. After agreeing on the scope and the tool list, the participants broke up into two groups to sort the tools: which ones were-to be included in the framework and which ones not, using the definition of the patientdirected knowledge tool (step 3). The two groups presented and discussed each other's findings, and agreed on a list of preliminary tools to be included. Based on this list, the two groups independently identified purposes of the tools, taking the discussed and agreed upon standard-definitions from step 2 into account (step 4). The outcomes of both groups were presented and discussed. This resulted in a first draft of the framework stating the preliminary included tools and their purposes. In step 5, the participants were split up in the two same groups, and were asked - using their research and practice knowledge - to identify core elements of the included tools. Once more, the findings of both groups were presented, discussed, and categorised leading to the second draft of the framework stating tool types, purposes and core elements.

Dividing the participants into two groups facilitated involving all participants, and avoiding any individual dominating the group. When there was disagreement the participants discussed the issue until consensus was reached.

The next step involved compiling the discussions and findings during a longer break and sent via email - together with the second draft of the framework - to participants taking part via a telephone conference at the end of day 1. The first day's discussions and findings were presented by DD to the participants calling in, and the other participants in the room. The former participants were given the opportunity to ask clarifying questions, and propose/suggest additional tools, purposes, and core elements (step 6). The draft framework was adapted with the input of the remote participants. A summary of the discussions and findings, together with the latest draft framework, were sent via email to participants $\mathrm{SH}$ and RR in Australia who could not participate in the teleconference. They would add their knowledge and input during the night (step 7), so that it could be discussed during day 2 of the meeting.

Day 2 was dedicated to fine-tuning the draft framework. Therefore, in step 8 the chair (JG) reviewed the possible tools and purposes with the participants to ensure that these were correct and complete, and if all agreed, confirming the purpose(s) for each tool. This exercise was repeated for the core elements (step 9). These steps resulted in the final draft of the framework as developed during the meeting.

\begin{tabular}{|c|l|l|}
\hline Step & What & Who \\
\hline 1 & Discussed and agreed on the scope. & $\begin{array}{l}\text { Participants in face-to-face } \\
\text { meeting }\end{array}$ \\
\hline 2 & $\begin{array}{l}\text { Discussed the list with tool types to familiarize with the tools and their } \\
\text { definitions, and if the list was complete. }\end{array}$ & $\begin{array}{l}\text { Participants in face-to-face } \\
\text { meeting }\end{array}$ \\
\hline 3 & $\begin{array}{l}\text { Including and excluding tools for the framework in subgroups; outcomes } \\
\text { presented and discussed with whole group. }\end{array}$ & $\begin{array}{l}\text { Participants face-to-face } \\
\text { meeting }\end{array}$ \\
\hline 4 & $\begin{array}{l}\text { Identified purposes of the tools in subgroups; discussed outcomes } \\
\text { presented and discussed with whole group. }\end{array}$ & $\begin{array}{l}\text { Participants face-to-face } \\
\text { meeting }\end{array}$ \\
\hline 5 & $\begin{array}{l}\text { Identified core elements of the included tools. } \\
\text { Participants face-to-face } \\
\text { meeting }\end{array}$ \\
\hline
\end{tabular}




\begin{tabular}{|c|l|l|}
\hline$\rightarrow$ First draft of conceptual framework ready \\
\hline 6 & $\begin{array}{l}\text { Presented and discussed draft framework; additional tools, purposes, } \\
\text { and core elements suggested. }\end{array}$ & $\begin{array}{l}\text { Teleconference } \\
\text { participants }\end{array}$ \\
\hline$\rightarrow$ Second draft of conceptual framework ready & Australian participants \\
\hline 7 & Received input on draft framework via email. & $\begin{array}{l}\text { Participants face-to-face } \\
\text { meeting }\end{array}$ \\
\hline 8 & $\begin{array}{l}\text { Fine-tuning: reviewed \& confirmed the possible tool types and purposes } \\
\text { to ensure that these were correct and complete. }\end{array}$ & $\begin{array}{l}\text { Participants face-to-face } \\
\text { meeting }\end{array}$ \\
\hline 9 & $\begin{array}{l}\text { Fine-tuning: reviewed \& confirmed the core elements to ensure that } \\
\text { these were correct and complete. }\end{array}$ \\
\hline$\rightarrow$ Final draft of the framework as developed during the meeting \\
\hline
\end{tabular}

Table 1: Step-by-step process during two-day consensus meeting

TVDW and DD finalized the draft framework based on the minutes, field notes and recorded data. This also entailed comparing the draft framework with existing frameworks and taxonomies. The comparison was done for two reasons: first, to compare language and terminology used, and second, to establish where the frameworks differed or were alike. The draft framework was distributed in the form of a scientific manuscript to the participants for final feedback. It took one face-to-face session with JG and two rounds by email with all coauthors before consensus was reached on the draft framework.

All participants completed a declaration of interests. The initiators and chair proposed how to deal with the declared interests. This was discussed and decided upon at the start of the meeting. The plenary parts of the meeting were audio-recorded and DD took minutes during both days. Furthermore, DD and TVDW compared the minutes and field, and adjusted them if needed. The adjusted minutes - checked against the recorded data - were shared afterwards with the participants for comments.

\subsection{Results}

The actual meeting was not as linear as described in the meeting protocol and methods section. It turned out to be an iterative process where discussions on tools and purposes lead to core elements and vice versa, but also prompting new or dismissed tool types to be (re-)included, such as care maps.

Meeting participants included the moderator (TVDW), secretary (DD), and 13 experts; nine participants attended in person (JG (chair), TA, GE, SF, LK, NS, DS, AS, ST), and four (MA, $A G, F L, P V)$ additionally took part in the teleconference. Two participants $(S H, R R)$ took part via email (see annex B). All participants took part in the iterative discussions by email afterwards to finalize the manuscript with the draft framework.

Step 1 was to select the tool types to be used when building the framework. Inclusion criteria were:

- Main target group are patients (family, care givers);

- Content driven instead of process oriented;

- Tool type globally known and used;

- Fits within the definition of the patient-directed knowledge tool (or not a knowledge tool). 
Based on the outcomes of the subgroups and decisions on these with all participants, we excluded seven tool types (not aimed directly at the patient) from the original list of 11 and added one tool perceived to be aimed at the patient directly but not of the list provided (see table 2). While discussing the selection with the whole group, we decided to split patient decision aids (PDA) into an encounter patient decision aid (ePDA) and an 'independent' PDA, leading to six tools. This distinction is important because the patients will use the former while talking with a healthcare professional and the latter independently, pre- or post-encounter. Tools such as action plans and decision guides were excluded because they concentrate on 'how' (process), and less on 'what' (knowledge). Decision coaching tools were deemed out of scope as well because these are aimed at the patient's coach, rather than primarily at the patient. During the telephone conference two tool types - question prompt list and decision box - were added because they support involving the patient in the care process, leading to a total of eight tools (see table 2 and annexes $F$ and D).

\begin{tabular}{|l|l|l|}
\hline$\#$ & Tool type & Included, excluded and remarks \\
\hline 1 & Decision tree & Preliminary included from list during face-to-face meeting \\
\hline 2 & Summary of clinical practice guideline & Preliminary included from list during face-to-face meeting \\
\hline & Patient decision aid (PDA) & \multirow{2}{*}{ Preliminary included from list during face-to-face meeting, } \\
and split into:
\end{tabular}

Table 2: overview of preliminary included and excluded tool types during face-to-face meeting and teleconference

From the preliminarily included tools, we deduced and described the possible purpose(s) of the tools. The purpose to inform patients was combined with 'to educate patients', because the emphasis was to make patients knowledgeable. Another reason to extendt the purpose was that informing and educating are often used interchangeably. We made a distinction between the purposes supporting decision-making, and that of engaging in shared decision-making. Even though tools can support decision-making by patient and professional, this does not necessarily mean that the tool also promotes shared decision-making. In the end, the listed possible purposes were aggregated into four purposes (see table 3):

- Inform or educate: provide information on the disease/complaint; what its treatment/care options are; how it can affect the patient's life; what the patient can do herself/himself to 
cope/deal with the disease/complaint and what the expected harms and benefits of treatment are.

- Provide recommendation(s): summarize evidence \& provide recommendation(s) - e.g. stemming from CPGs - regarding care option(s).

- Support decision-making: to support decision-making by the patient (and not decision-making together with a healthcare professional): provide information on option(s) (including doing nothing, watchful waiting); harms and benefits, risks thereof; elicit values, preferences and contemplation so that patients can choose the treatment/care or option that suits best.

- Engage in shared decision-making: invite, stimulate or instruct the patient to decide together with healthcare provider on treatment/care.

When discussing possible purposes, alleviating fear(s), and decreasing decisional conflict were mentioned as well. The participants concluded they were outcomes, and were therefore not listed as a purpose. Communication was not included as a purpose. To engage patients, or exchange knowledge/information with a patient, as a healthcare professional, you need to communicate (verbally and non-verbally) with the patient. It is an overarching means, not a purpose in itself.

The next step was to identify core elements of the included patient-directed knowledge tool types. The participants compared the tool types, identified recurring elements within tool types and between tools. Furthermore, on the basis of existing frameworks and taxonomies they determined which elements should be included in a tool type (prototypical), even though existing examples of those tool types may not include these elements. Mentioned elements were for example, (link to) evidence, background on condition, care or treatment options/alternatives, burden (and evidence thereof), relative importance of outcomes as different patients may weigh importance of outcomes differently (43). Also, possible effects of the tools, such as improving the knowledge of the patient, improving patient's expectations of the treatment, impact on their health and quality of life, improving patient-provider communication, and changes in decisionmaking behaviour) were discussed as possible purposes. Whilst discussing the elements, explicit mentioning of harms and benefits of treatment/care in the tools was stressed by the participants. Harms were especially emphasised as these are often not mentioned or mentioned less often than benefits (44-46). At the end, the core elements were put into preliminary categories.

When discussing the framework, the purposes, and core elements of the tool types, several issues surfaced. First, at the beginning of the meeting, one participant stated that the patientdirected knowledge tools are preferably based on trustworthy clinical practice guidelines. However, there appears to be a pivotal point between PDAs and CPGs: the element 'recommendation'. A CPG centres on recommendations, meaning that the healthcare professional needs to 'translate' it together with the patient to the patient characteristics and preferences (47), whereas decision aids aim to acquaint patients with information about choices and available options, including watchful monitoring. Of late, clinical practice guidelines (recommendations) are created or re-written to include these elements as well, but it is not a common practice yet $(21,48,49)$. 
As one of the participants involved in the meeting noted: "Looking through a future lens and decision making view: [there will be] a set of guidelines that don't [provide room for contemplation], and 'innovator' guidelines that do list options."

[quote on reconciling clinical practical guidelines and shared decision-making] (50)

Furthermore, some participants argued using other sources than CPGs as a basis for patientdirected knowledge tools, such as evidence summaries or systematic reviews, and questioned how to include qualitative data in the evidence base (51).

We also discussed whether the framework should be discretionary or prototypical. Discretionary meaning that the core elements mentioned in the framework are optional; and prototypical indicating that we should aim to include the core elements listed in the framework in patientdirected knowledge tools. For example, current tools mostly disregard core elements such as harms and the need to elicit patient's values (52). Often only one option is stated, instead of giving a complete overview of options, including watchful waiting when relevant (44). We decided that it would be a descriptive and prototypical framework.

This decision resulted in one participant to say: "We are wasting time on patient education material without options; we need to be bold." [quote on importance of a prototypical framework]

Finalizing the draft framework entailed checking and rewriting the wording used in the framework, and reorganizing the core element categories (7, 53-55). The category 'outcomes', which refers to the effect(s) of the tools, was not included in the framework. Possible effects proposed and discussed during the meeting were: improved knowledge acquisition by the patient, more realistic or informed expectations, decreased decision burden/stress or less regret. As most of these outcomes have not been confirmed by research (yet), we felt it premature to include this category in the framework (56).

The draft framework at the end of the meeting contained eight tools (see table 2), of which two 'care map and decision box - were conditionally included as we were not entirely sure if they were patient-directed knowledge tools. The framework in the article contains five tool types, because when looking further into the tools 'question prompt list' and 'decision box', we decided that these tools belong to the tool type 'encounter PDAs, and they were therefore removed from the framework as separate tool types. The tool type 'care map' was left out as well, as they are also called 'care pathways' $(16,19)$, and we excluded the latter at the beginning of the meeting. It was also suggested in the feedback rounds via email to leave out the tool 'decision tree'. Due to renewed attention to this tool type - e.g. digitalising CPGs into decision trees to enhance use by healthcare professionals and patients (57-59), and because the tool was not included conditionally as were the tools 'care map' and 'decision box', it is still part of the draft framework.

The final working draft of the framework contains consists five patient-directed tool types, and consists of two parts: one stating the four purposes of the tools (see table 3) and the other the core elements (see table 4 (see annex E)). 


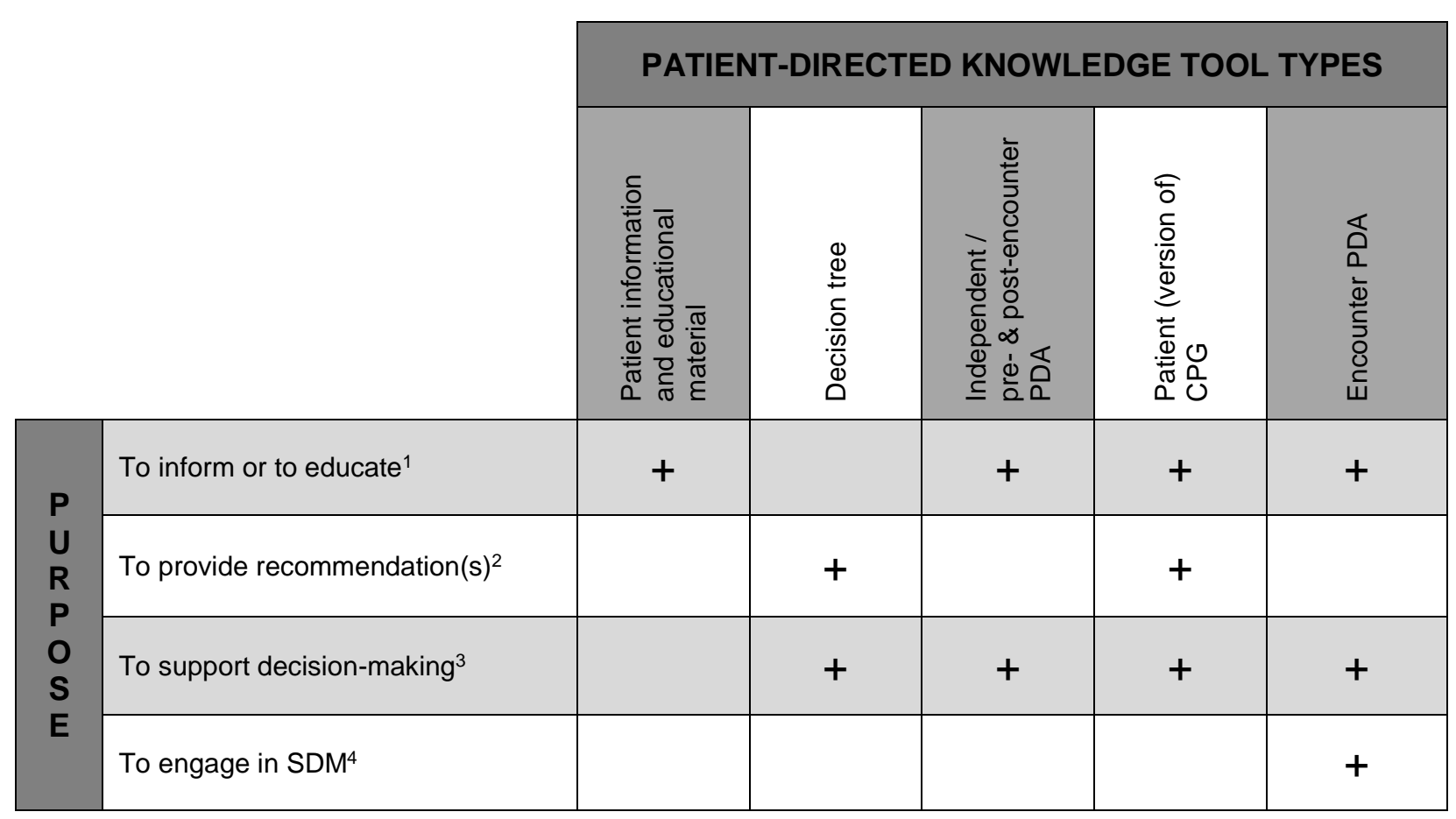

Table 3: Draft framework part 1: purposes of patient directed knowledge tools

\subsection{Discussion and conclusion}

\subsection{Discussion}

We developed a working (or draft) framework containing five patient-directed knowledge tool types describing the purposes and (prototypical) core elements of these tools. There already exist other related frameworks; however, these tend to focus on patient decision aids. At the other end of the spectrum, the CCCG taxonomies take a far broader view, incorporating all interventions for communication without a specific focus on knowledge tools, and without delineating the core elements of the interventions $(29,31,53,60)$.

\subsection{Conclusions}

As there exists an abundance of different patient-directed knowledge tools, with different names and mostly unclear definitions, our working draftframework can help tool developers, people who commission the development of these tools, policy makers, patients and healthcare professionals to discern between the different tools, and to identify to which tool type it belongs, which purposes it serves and which core elements it should contain. Possibly, when there is more clarity on development, content and purpose of the tool, it may lead to a better understanding of the roles of, and uptake of, the tool. We feel that the field of tools development and implementation might profit from initiatives such as this one; it might provide the sought for direction and leadership.

Regarding the discussion whether to use only CPGs as basis for patient-directed knowledge tools, such as ePDAs, the group discussed the benefits of harmonizing evidence summaries across these tools, also within the context of updating content. Such CPGs and accompanying 
PDAs have been developed, for example within the MAGIC-project, providing proof of concept for this approach $(37,49,61)$.

New (types of) tools will emerge. We can use these to test our working framework by assessing if the new tool fits within the current types, whether it requires adding a new tool type, additional purposes or core elements to the framework, or if it is a different type of tool not belonging within the framework.

Next steps are to review the framework thoroughly with a broader group of stakeholders $s_{2}$ including patients and other users. Working with the framework will demonstrate if it is helpful and complete regarding tool types, purposes, and core elements. For example, it may be helpful to discuss whether or not merging of the last two purposes (support and engage in shared decision-making) would be a useful revision to the framework. A first cautious check of the framework took place at the International Shared Decision Making (ISDM) Conference, Lyon, in 2017 (62), meeting general agreement and receiving no major comments with respect to content. The framework, a work in progress, could be further enhanced by identifying which effect outcomes of the tools are supported by evidence, and describing the core elements in more detail. Additionally, it is important to consider the implementation and use of these tools, for instance by exploring what skills or support patients need to be able to use them (63).

A potential weakness was the extent to which the participants are involved in this subject. We tried to counteract this by having a group consisting of participants with different expertise and from various backgrounds, and by providing descriptions of the discussed tools before the meeting. Also, the group was limited in its size. Therefore, the framework was not presented as finished but as a draft framework. Another risk of the group composition and size could be that it obscured tools as not being within scope. There were no patient representatives present during the meeting; however, two participants ( $\mathrm{SH}$ and $\mathrm{RR}$ ) with extensive experience in health consumer participation and patient-centred care commented and added to the work of the group at the end of day 1. Having (most of) the participants together for a prolonged time in one room, contributed to enhanced participation, open discussions and the liberty to ask each other questions, making it possible to respond to non-verbal communication, and leading to a first draft of the conceptual framework.

\subsection{Implications for practice}

Our working framework on different types of patient-directed knowledge tools is aimed at developers, and possibly at those who commission the development of tools, healthcare professionals and policy makers, and hopefully adds to provides clarity on the different knowledge tools by stating the purpose(s) they serve and which core elements they should include. The ambition is that tool types are no longer developed without a clear definition and use. This working framework will make it easier for developers to identify when to develop which patient-directed knowledge tool and what core elements to include, and to help patients and professionals to understand when to use which tool type. 


$\begin{array}{ll}\text { Abbreviations } \\ \text { CCCG } & \text { Cochrane Consumer \& Communication Group } \\ \text { CPG } & \text { Clinical practice guideline } \\ \text { ePDA } & \text { Encounter patient decision aid } \\ \text { GIN } & \text { Guideline International Network } \\ \text { GRADE } & \text { Grading of Recommendations Assessment, Development and Evaluation } \\ \text { IPDAS } & \text { International Patient Decision Aid Standards } \\ \text { ISDM } & \text { International Shared Decision Making conference } \\ \text { PDA } & \text { Patient decision aid } \\ \text { QPL } & \text { Question prompt list } \\ \text { SDM } & \text { Shared decision making }\end{array}$

Declarations

Ethics approval and consent to participate:

NOT APPLICABLE

Consent for publication:

NOT APPLICABLE

Availability of data and material:

All data processed or analysed during the current study are included in this published article.

Funding:

This meeting was carried out as part of research funded by ZonMw, the Netherlands organization for health research and development, Development of patient information and patient decision aids alongside clinical practice guidelines, project number 0-83900-98-350, and as part of the PhD-research of DD, made possible by the Knowledge Institute of Medical Specialists, ZonMw and Maastricht University/School for Care and Public Health Research Institute CAPHRI.

Additional funding was acquired for travel and lodging expenses of the participants. The National Institute for the Quality of Health Care and the Knowledge Institute of Medical Specialists each contributed 2,500 Euros, and Maastricht University contributed 5,000 Euros.

Authors' contributions:

DD and TVDW initiated this work. With TVDW being end accountable for the project and fund raising. AS was actively involved in hosting the meeting and during the writing phase. JG was actively involved during the preparatory phase and chaired the meeting. DD wrote the first draft of the paper, supervised by TVDW. All authors contributed actively to the subsequent drafts of the paper. 


\section{References}

1. Sackett DL, Rosenberg WM, Gray JA, Haynes RB, Richardson WS. Evidence based medicine: what it is and what it isn't. Bmj. 1996;312(7023):71-2.

2. Charles C, Gafni A, Whelan T. Shared decision-making in the medical encounter: what does it mean? (or it takes at least two to tango). Soc Sci Med. 1997;44(5):681-92.

3. Patient Engagement: Technical Series on Safer Primary Care. Geneva: World Health Organization; 2016. Contract No.: Licence: CC BY-NC-SA 3.0 IGO.

4. Boivin A, Green J, van der Meulen J, Legare F, Nolte E. Why consider patients' preferences? A discourse analysis of clinical practice guideline developers. Medical care. 2009;47(8):908-15.

5. Doyle $C$, Lennox L, Bell D. A systematic review of evidence on the links between patient experience and clinical safety and effectiveness. BMJ Open. 2013;3(1).

6. Street RL, Jr., Krupat E, Bell RA, Kravitz RL, Haidet P. Beliefs about control in the physicianpatient relationship: effect on communication in medical encounters. J Gen Intern Med. 2003;18(8):60916.

7. Stacey D, Legare F, Col NF, Bennett CL, Barry MJ, Eden KB, et al. Decision aids for people facing health treatment or screening decisions. The Cochrane database of systematic reviews.

2014(1):CD001431.

8. Rathert C, Wyrwich MD, Boren SA. Patient-centered care and outcomes: a systematic review of the literature. Med Care Res Rev. 2013;70(4):351-79.

9. Shay LA, Lafata JE. Where is the evidence? A systematic review of shared decision making and patient outcomes. Med Decis Making. 2015;35(1):114-31.

10. Ubel PA, Angott AM, Zikmund-Fisher BJ. Physicians recommend different treatments for patients than they would choose for themselves. Arch Intern Med. 2011;171(7):630-4.

11. Mulley AG, Trimble C, Elwyn G. Stop the silent misdiagnosis: patients' preferences matter. BMJ. 2012;345:e6572.

12. Stalmeier PF, van Tol-Geerdink JJ, van Lin EN, Schimmel E, Huizenga H, van Daal WA, et al. Doctors' and patients' preferences for participation and treatment in curative prostate cancer radiotherapy. J Clin Oncol. 2007;25(21):3096-100.

13. Stacey D, Hill S. Patient-direct and patient- mediated KT interventions In: Straus S, Tetroe J, Graham I, editors. Knowledge Translation in Health Care: Moving from Evidence to Practice. second ed. Hoboken: John Wiley \& Sons; 2013. p. 197-211.

14. Brouwers M, Stacey D, O'Connor A. Knowledge translation tools. In: Straus S, Tetroe J, Graham I, editors. Knowledge Translation in Health Care: Moving from Evidence to Practice. second ed. Hoboken: John Wiley \& Sons, Ltd.; 2013. p. 50-62.

15. Dreesens D, Burgers J, Kremer L, Van der Weijden T. Lost in definitions: reducing duplication and clarifying definitions of knowledge and decision support tools. A modified RAND Delphi consenus study. submitted. 2018.

16. Dreesens D, Kremer L, van der Weijden T. The Dutch chaos case: a scoping review of knowledge and decision support tools available to clinicians in the Netherlands. submitted. 2018.

17. Brouwers M, Stacey D, O'Connor A. Knowledge creation: synthesis, tools and products. CMAJ : Canadian Medical Association journal = journal de l'Association medicale canadienne. 2010;182(2):E6872.

18. Straus SE, Tetroe J, Graham I. Defining knowledge translation. CMAJ : Canadian Medical Association journal = journal de l'Association medicale canadienne. 2009;181(3-4):165-8.

19. De Bleser L, Depreitere R, De Waele K, Vanhaecht K, Vlayen J, Sermeus W. Defining pathways. J Nurs Manag. 2006;14(7):553-63. 
20. Stiggelbout AM, Timmermans DR. Revisiting decision aids: about definitions and classifications. Med Decis Making. 2010;30(6):696-8.

21. Charles C, Gafni A, Freeman E. Implementing shared treatment decision making and treatment decision aids: a cautionary tale Psicooncología. 2010;7(2-3):243-55.

22. Elwyn G, Scholl I, Tietbohl C, Mann M, Edwards AG, Clay C, et al. "Many miles to go ...": a systematic review of the implementation of patient decision support interventions into routine clinical practice. BMC medical informatics and decision making. 2013;13 Suppl 2:S14.

23. Zuiderent-Jerak T, Forland F, Macbeth F. Guidelines should reflect all knowledge, not just clinical trials. Bmj. 2012;345:e6702.

24. Zuiderent-Jerak T, Jerak-Zuiderent S, van de Bovenkamp HM, Swan TS, Hakkaart-van Roijen L, Brouwer W, et al. Variatie in richtlijnen; wat is het probleem? [Variance in guidelines; what is the problem?]. The Hague, The Netherlands: Regieraad Kwaliteit van Zorg; 2011 April 2011.

25. Carman KL, Dardess P, Maurer M, Sofaer S, Adams K, Bechtel C, et al. Patient and family engagement: a framework for understanding the elements and developing interventions and policies. Health affairs. 2013;32(2):223-31.

26. Entwistle VA, Watt IS. Patient involvement in treatment decision-making: the case for a broader conceptual framework. Patient Educ Couns. 2006;63(3):268-78.

27. Wensing $\mathrm{M}$, Baker R. Patient involvement in general practice care: a pragmatic framework. Eur J Gen Pract. 2003;9(2):62-5.

28. Grande SW, Faber MJ, Durand MA, Thompson R, Elwyn G. A classification model of patient engagement methods and assessment of their feasibility in real-world settings. Patient Educ Couns. 2014;95(2):281-7.

29. Elwyn G, O'Connor A, Stacey D, Volk R, Edwards A, Coulter A, et al. Developing a quality criteria framework for patient decision aids: online international Delphi consensus process. Bmj. 2006;333(7565):417.

30. IPDAS checklist. International Patient Decision Aid Standards Collaboration.

31. IPDAS. IPDAS 2005: Criteria for Judging the Quality of Patient Decision Aids. International Patient Decision Aid Standards Collaboration; 2005.

32. Durand MA, Stiel M, Boivin J, Elwyn G. Where is the theory? Evaluating the theoretical frameworks described in decision support technologies. Patient Educ Couns. 2008;71(1):125-35.

33. O'Connor AM, Tugwell P, Wells GA, Elmslie T, Jolly E, Hollingworth $G$, et al. A decision aid for women considering hormone therapy after menopause: decision support framework and evaluation. Patient Educ Couns. 1998;33(3):267-79.

34. Patient Decision Aids: Ottawa Decision Support Framework (ODSF) Ottawa: Ottawa Hospital Research Institute; [Available from: https://decisionaid.ohri.ca/odsf.html.

35. Outcomes of Interest to the Cochrane Consumers \& Communication Review Group. CCCG Melbourne: La Trobe University; 2012 [Approved (Hill, S.)]. Available from: http://cccrg.cochrane.org/author-resources.

36. Nilsen P. Making sense of implementation theories, models and frameworks. Implement Sci. 2015;10:53.

37. Elwyn G, Quinlan C, Mulley A, Agoritsas T, Vandvik PO, Guyatt G. Trustworthy guidelines excellent; customized care tools - even better. BMC Med. 2015;13:199.

38. O'Brien BC, Harris IB, Beckman TJ, Reed DA, Cook DA. Standards for reporting qualitative research: a synthesis of recommendations. Academic medicine : journal of the Association of American Medical Colleges. 2014;89(9):1245-51.

39. Creatief Denken: brainstormtechnieken [Creative thinking; brainstorm techniques]: Creatief Denken; 2015 [Available from: https://www.creatiefdenken.com/nl/techniek/brainstormtechniekenoverzicht.php. 
40. Muller G. Meeting methods - pressure cooker. 2015.

41. Dirkse-Hulscher S, Talen A. Het grote werkvormenboek (The big book on interactive work methods). Amsterdam: Boom Ultgevers; 2007.

42. The Savvy Professional; Increasing Your Professional IQ. 2015.

43. Alonso-Coello P, Schunemann HJ, Moberg J, Brignardello-Petersen R, AkI EA, Davoli M, et al. GRADE Evidence to Decision (EtD) frameworks: a systematic and transparent approach to making well informed healthcare choices. 1: Introduction. Bmj. 2016;353:i2016.

44. Snijders HS, Kunneman M, Bonsing BA, de Vries AC, Tollenaar RA, Pieterse AH, et al. Preoperative risk information and patient involvement in surgical treatment for rectal and sigmoid cancer. Colorectal Dis. 2014;16(2):043-9.

45. Hoffmann TC, Del Mar C. Clinicians' Expectations of the Benefits and Harms of Treatments, Screening, and Tests: A Systematic Review. JAMA internal medicine. 2017;177(3):407-19.

46. Hoffmann TC, Del Mar C. Patients' expectations of the benefits and harms of treatments, screening, and tests: a systematic review. JAMA internal medicine. 2015;175(2):274-86.

47. Armstrong MJ, Gronseth GS. Approach to assessing and using clinical practice guidelines. Neurol Clin Pract. 2018;8(1):58-61.

48. O'Connor A, G Elwyn. IPDAS 2005: Criteria for Judging the Quality of Patient Decision Aids. In: -, editor. - -ed. -: IPDAS OHRI; 2005. p. 2-3.

49. Vandvik PO, Fog-Heen A, Agoritsas T. SHARE-IT: rapid production of online decision aids linked to guidelines for point-of-care shared-decision making. Cochrane Colloquium 2016; Seoul: The Cochrane Collaboration; 2016.

50. Guyatt GH, Oxman AD, Kunz R, Falck-Ytter Y, Vist GE, Liberati A, et al. Going from evidence to recommendations. BMJ. 2008;336(7652):1049-51.

51. Wieringa S, Dreesens D, Forland F, Hulshof C, Lukersmith S, Macbeth F, et al. Different knowledge, different styles of reasoning: a challenge for guideline development. BMJ Evid Based Med. 2018;23(3):87-91.

52. CONSORT. Harms - All important harms or unintended effects in each group Ottowa: CONSORT; 2010 [Available from: http://www.consort-statement.org/checklists/view/32--consort-2010/116-harms.

53. Kaufman J, Ryan R, Glenton C, Lewin S, Bosch-Capblanch X, Cartier Y, et al. Childhood vaccination communication outcomes unpacked and organized in a taxonomy to facilitate core outcome establishment. Journal of clinical epidemiology. 2017;84:173-84.

54. Willis N, Hill S, Kaufman J, Lewin S, Kis-Rigo J, De Castro Freire SB, et al. "Communicate to vaccinate": the development of a taxonomy of communication interventions to improve routine childhood vaccination. BMC international health and human rights. 2013;13:23.

55. Group CCCR. Taxonomy of relevant outcomes. Cochrane Consumers \& Communications Review Group; 2012.

56. Fonhus MS, Dalsbo TK, Johansen M, Fretheim A, Skirbekk H, Flottorp SA. Patient-mediated interventions to improve professional practice. The Cochrane database of systematic reviews. 2018;9:CD012472.

57. Antimicrobial stewardship: systems and processes for effective antimicrobial medicine use London: NICE; 2015 [Available from: https://www.nice.org.uk/guidance/NG15.

58. De Vries AW, Klijn FAJ, Vernooij RW, Aben KH, De Reijke TM. Prostaatkankerrichtlijn: een routekaart in Oncoguide, beslisbomen en informatiestandaard (Prostate cancer guidelin: a route map in Oncology, decision trees and information standard). Tijdschr Urol [Internet]. 2019.

59. Verstijnen I, Nistelrooij LPJv, Enzing JJ, Timmermans NGL, Heer PD, Sent D. Plant a tree to stay tuned-in. Interactive flowcharts known as CareTrees ("Zorgbomen") help to keep guidelines up-to-date. Guidelines International Network 2015 Conference; Amsterdam2015. 
60. Kaufman J, Ames H, Bosch-Capblanch X, Cartier Y, Cliff J, Glenton C, et al. The comprehensive 'Communicate to Vaccinate' taxonomy of communication interventions for childhood vaccination in routine and campaign contexts. BMC public health. 2017;17(1):423.

61. MAGIC; making GRADE the irresistible choice Oslo: MAGIC Association; 2013 [Available from: http://magicproject.org/.

62. Dreesens D, van der Weijden T, Grimshaw J. Supporting patient-centered care; making knowledge tools more accessible to patients, and professionals. ISDM 2017; 4th July; Lyon, France2017. 63. Hill S, Sofra TA. How could health information be improved? Recommended actions from the Victorian Consultation on Health Literacy. Aust Health Rev. 2017;42(2):134-9.

\section{Legends}

Legend of table 3: Framework part 1: purposes of patient directed knowledge tools:

+ knowledge tool serves purpose

1 To inform or to educate: provide information on the disease/complaint; what its treatment/care options are; how it can affect the patient's life; what the patient can do herself/himself to cope/deal with the disease/complaint and what are the expected harms and benefits of treatment.

2 To provide recommendation(s): summarize evidence \& provides recommendation(s) - e.g. stemming from guidelines - regarding care option(s).

3 To support decision making by the patient (and not decision making together with a healthcare professional): provide information on option(s) (including doing nothing, watchful waiting); harms and benefits, risks thereof; elicit values, preferences and contemplation so that patients can choose the treatment/care or option that suits best. Possibly indicate which \% of patients in a similar situation chose which option.

4 To engage in shared decision-making: invite, stimulate or instruct the patient to decide together with healthcare provider on treatment/care.

Abbreviations:

- CPG: clinical practice guideline

- PDA: patient decision aid

- SDM: shared decision making 


\section{Annexes}

\section{Annex A - Meeting protocol}

POW $(\mathrm{W})$ - purpose, outcome, why - of meeting

\begin{tabular}{|l|l|l|}
\hline Purpose & $\begin{array}{l}\text { Statement of meeting } \\
\text { objective(s) }\end{array}$ & $\begin{array}{l}\text { To develop a framework that makes it possible to position } \\
\text { knowledge and decision support tool types along 3 or 4 } \\
\text { axes/dimensions, next to clarifying their mutual relations. By } \\
\text { doing so, this framework would help tool developers which tool } \\
\text { needs to be developed in which case. }\end{array}$ \\
\hline Outcome & $\begin{array}{l}\text { More specific; it is } \\
\text { what you have when } \\
\text { you walk out of the } \\
\text { door of the meeting, } \\
\text { the desired result }\end{array}$ & $\begin{array}{l}\text { A framework to be presented to the knowledge and decision } \\
\text { support tools community of developers, and, implementers, } \\
\text { possibly even users, to test whether it is usable and suitable. } \\
\text { A framework that can be adjusted to the national situation. } \\
\text { A plan how to ensure that stakeholders worldwide are informed } \\
\text { about the framework. }\end{array}$ \\
\hline Why & $\begin{array}{l}\text { The rationale for } \\
\text { achieving the meeting } \\
\text { objective(s) and each } \\
\text { individual's "what's in } \\
\text { it for me" }\end{array}$ & $\begin{array}{l}\text { To meet a heart-felt need by developers, implementers and users } \\
\text { of knowledge and decision support tools to clarify the different } \\
\text { types of tools and how they are mutually related, so that } \\
\text { developers can develop the right tool for the right job. } \\
\text { To contribute to the different domains of research of the } \\
\text { participants, and unifying terminology in and across domains. }\end{array}$ \\
\hline
\end{tabular}

Meeting programme

\begin{tabular}{|c|c|c|c|}
\hline \multicolumn{2}{|r|}{ DAY $1\left(\right.$ Feb 23 $\left.{ }^{\text {rd }}\right)$} & \multicolumn{2}{|r|}{ DAY $2\left(\right.$ Feb 24 $\left.{ }^{\text {th }}\right)$} \\
\hline $8: 30$ & $\begin{array}{l}\text { - Welcome } \\
\text { - Introductions } \\
\text { - Presentation } \\
\text { Whole group }\end{array}$ & 9:00 & $\begin{array}{l}\text { Reflection \& summarizing day } 1 \\
\text { Whole group }\end{array}$ \\
\hline 9:00 & $\begin{array}{l}\text { Reflection on: } \\
\text { - Scope of invitational (step 1) } \\
\text { - Assessing list of knowledge tool types } \\
\text { familiar and complete types (step 2) } \\
\text { Whole group }\end{array}$ & & $\begin{array}{l}\text { Fine tuning and finalizing (1): (step } 8) \\
\text { - Purposes of tools (part } 1 \text { ) } \\
\text { - Checking/ticking boxes of part } 1 \text { of } \\
\text { framework } \\
\text { Presentation subgroup results \& whole group }\end{array}$ \\
\hline $10: 30$ & Coffee break & $10: 30$ & Coffee break \\
\hline & $\begin{array}{l}\text { Sorting exercise: } \\
\text { - In/excluding knowledge tools (step 3) } \\
\text { - Identifying purposes of tools (step 4) } \\
\text { In subgroups }\end{array}$ & & $\begin{array}{l}\text { Fine tuning and finalizing (2): (step 9) } \\
\text { - Core ingredients of tools (part } 1 \text { ) } \\
\text { - Checking/ticking boxes of part } 2 \text { of } \\
\text { framework } \\
\text { Presentation subgroup results \& whole group }\end{array}$ \\
\hline $12: 30$ & Lunch break & $12: 30$ & Follow-up and next steps \\
\hline & $\begin{array}{l}\text { Identifying core ingredients (step 5) } \\
\text { In subgroups }\end{array}$ & $13: 00$ & Barometer \& end of day two \\
\hline 15:00 & $\begin{array}{l}\text { Break - preparing material for } \\
\text { teleconference } \\
\text { Whole group }\end{array}$ & & \\
\hline
\end{tabular}




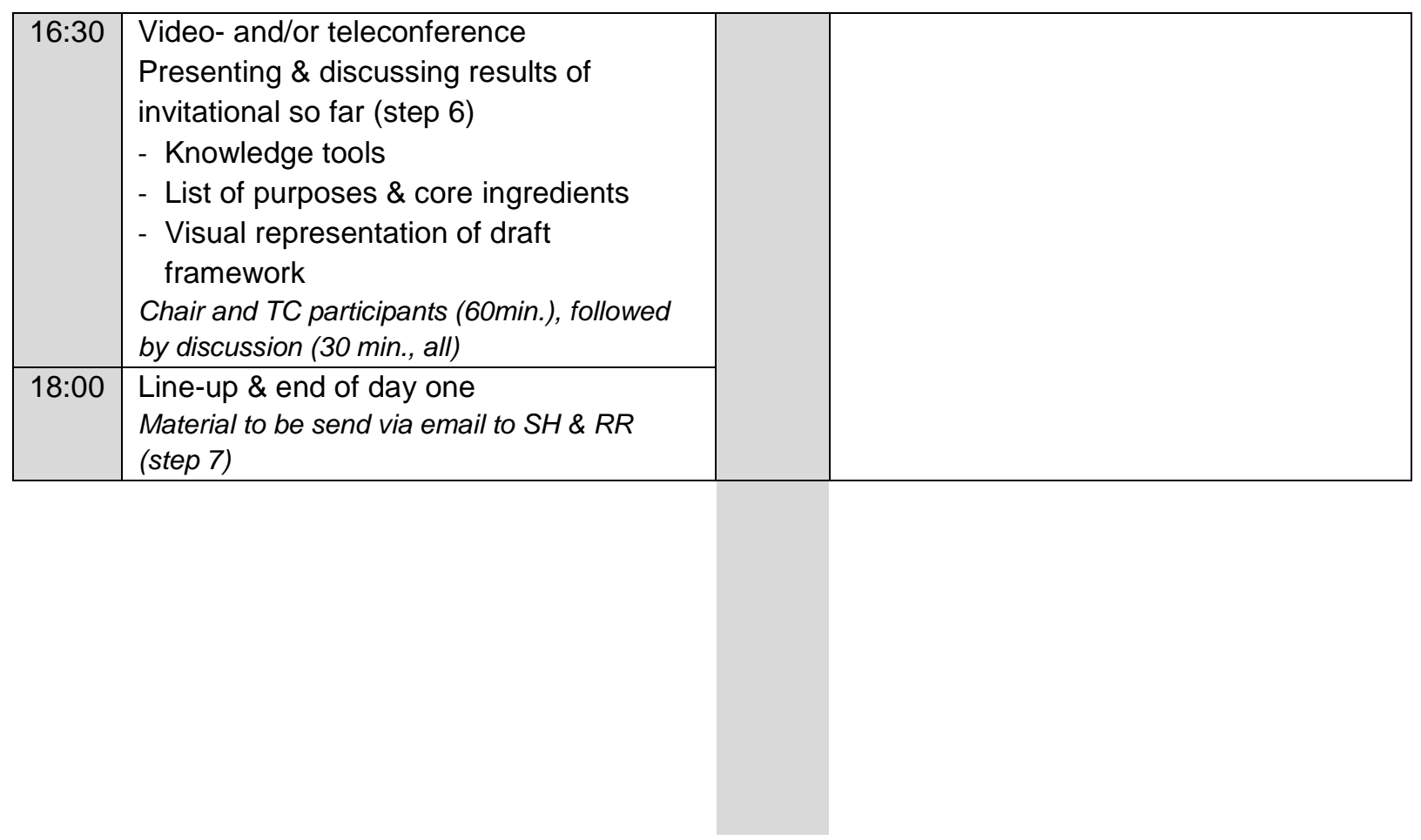


Annex B - Participants consensus meeting invitational

\begin{tabular}{|c|c|c|c|c|}
\hline Country & Name & Affiliation & Background \& expertise & Role \\
\hline \multicolumn{5}{|c|}{ Present face-to-face meeting in Leiden } \\
\hline CAN & Jeremy Grimshaw & Ottawa Hospital Research Institute & General practitioner; knowledge transfer; implementation & Chair \\
\hline $\mathrm{NL}$ & Dunja Dreesens & $\begin{array}{l}\text { Maastricht University, Knowledge Institute of Medical } \\
\text { Specialists }\end{array}$ & Health \& social sciences; guidelines; health policy & Secretary \\
\hline $\mathrm{NL}$ & $\begin{array}{l}\text { Trudy van der } \\
\text { Weijden }\end{array}$ & Maastricht University & Epidemiologist; guidelines; SDM; implementation & Moderator \\
\hline $\mathrm{CH}$ & Thomas Agoritsas & University of Geneva & Internal medicine; epidemiologist; evidence-based health care & Participant \\
\hline USA & Glyn Elwyn & $\begin{array}{l}\text { The Dartmouth Institute for Health Policy and Clinical } \\
\text { Practice }\end{array}$ & General practitioner; SDM; decision aids & Participant \\
\hline $\mathrm{N}$ & Signe Flottorp & Norwegian Institute of Public Health, University of Oslo & General practitioner; health services; chronic disease & Participant \\
\hline NL & Leontien Kremer & National Institute for the Quality of Health Care NL & $\begin{array}{l}\text { Paediatrician; systematic reviews; guidelines; evidence-based } \\
\text { health care }\end{array}$ & Participant \\
\hline CAN & Nancy Santesso & McMaster University & Dietician; GRADE; communication to patients/public; guidelines & Participant \\
\hline CAN & Dawn Stacey & Ottawa Hospital Research Institute & Nurse; systematic reviews; decision aids & Participant \\
\hline NL & Anne Stiggelbout & Leiden University & $\begin{array}{l}\text { Human nutrition; medical decision making; patient preferences; } \\
\text { costs and benefits }\end{array}$ & Participant \\
\hline UK & Shaun Treweek & DECIDE, University of Aberdeen & Physicist; health services; trial design & Participant \\
\hline \multicolumn{5}{|c|}{ Participated in teleconference } \\
\hline USA & Melissa Armstrong & University of Florida & Neurologist; engaging patients; guidelines & Participant \\
\hline CAN & Anna Gagliardi & University of Toronto & $\begin{array}{l}\text { Implementation science, patient-centered care, patient } \\
\text { engagement }\end{array}$ & Participant \\
\hline CAN & France Légaré & Université LAVAL & Architect; family physician; implementation; SDM & Participant \\
\hline $\mathrm{N}$ & Per Vandvik & DECIDE, University of Oslo & $\begin{array}{l}\text { Physician; evidence-based health care; GRADE; decision } \\
\text { making }\end{array}$ & Participant \\
\hline \multicolumn{5}{|c|}{ Participated via email } \\
\hline AUS & Sophie Hill* & $\begin{array}{l}\text { La Trobe University Melbourne, Cochrane Consumers } \\
\text { and Communication Group }\end{array}$ & $\begin{array}{l}\text { Health communication and participation; public health; health } \\
\text { literacy }\end{array}$ & Participant \\
\hline AUS & Rebecca Ryan & $\begin{array}{l}\text { La Trobe University Melbourne, Cochrane Consumers } \\
\text { and Communication Group }\end{array}$ & $\begin{array}{l}\text { Pharmacology \& neuroscience; consumer participation; risk } \\
\text { communication }\end{array}$ & Participant \\
\hline
\end{tabular}

* Sophie Hill was willing to participate in teleconference. However, due to the time difference this proved difficult. 


\section{Annex C - List with references provided to participants before the invitational meeting}

1. Michie S, Richardson M, Johnston M, Abraham C, Francis J, Hardeman W, et al. The behavior change technique taxonomy ( $v 1$ ) of 93 hierarchically clustered techniques: building an international consensus for the reporting of behavior change interventions. Annals of behavioral medicine : a publication of the Society of Behavioral Medicine. 2013 Aug;46(1):81-95. PubMed PMID: 23512568.

2. Grande SW, Faber MJ, Durand MA, Thompson R, Elwyn G. A classification model of patient engagement methods and assessment of their feasibility in real-world settings. Patient Educ Couns. 2014 May;95(2):281-7. PubMed PMID: 24582473.

3. Elwyn G, Lloyd A, May C, van der Weijden T, Stiggelbout A, Edwards A, et al. Collaborative deliberation: a model for patient care. Patient Educ Couns. 2014 Nov;97(2):158-64. PubMed PMID: 25175366.

4. Willis N, Hill S, Kaufman J, Lewin S, Kis-Rigo J, De Castro Freire SB, et al. "Communicate to vaccinate": the development of a taxonomy of communication interventions to improve routine childhood vaccination. BMC international health and human rights. 2013;13:23. PubMed PMID: 23663327. Pubmed Central PMCID: 3655915.

5. Vandvik PO, Brandt L, Alonso-Coello P, Treweek S, AkI EA, Kristiansen A, et al. Creating Clinical Practice Guidelines We Can Trust, Use, and Share: A New Era Is Imminent. Chest. 2013;144(2):3819.

6. Schoemaker C, Van Everdingen J, Van Loon J. De toekomst van richtlijnen; een verkenning aan de hand van vier perspectieven van de VTV-2014. Ned Tijdschr Geneeskd. 2015;159(A8347):1-5 (?).

7. Agoritsas T, Heen AF, Brandt L, Alonso-Coello P, Kristiansen A, AkI EA, et al. Decision aids that really promote shared decision making: the pace quickens. Bmj. 2015;350:g7624. PubMed PMID: 25670178. Pubmed Central PMCID: 4707568.

8. Leeman J, Baernholdt M, Sandelowski M. Developing a theory-based taxonomy of methods for implementing change in practice. Journal of advanced nursing. 2007 Apr;58(2):191-200. PubMed PMID: 17445022.

9. Lowe D, Ryan R, Santesso N, Hill S. Development of a taxonomy of interventions to organise the evidence on consumers' medicines use. Patient Educ Couns. 2011 Nov;85(2):e101-7. PubMed PMID: 21036505.

10. Charnock D, Shepperd S, Needham G, Gann R. DISCERN: an instrument for judging the quality of written consumer health information on treatment choices. Journal of epidemiology and community health. 1999 Feb;53(2):105-11. PubMed PMID: 10396471. Pubmed Central PMCID: 1756830.

11. Coulter A, Ellins J. Effectiveness of strategies for informing, educating, and involving patients. Bmj. 2007 Jul 7;335(7609):24-7. PubMed PMID: 17615222. Pubmed Central PMCID: 1910640.

12. Gillies K, Entwistle V, Treweek SP, Fraser C, Williamson PR, Campbell MK. Evaluation of interventions for informed consent for randomised controlled trials (ELICIT): protocol for a systematic review of the literature and identification of a core outcome set using a Delphi survey. Trials. 2015;16:484. PubMed PMID: 26507504. Pubmed Central PMCID: 4624669.

13. Giguere AM, Labrecque M, Haynes RB, Grad R, Pluye P, Legare F, et al. Evidence summaries (decision boxes) to prepare clinicians for shared decision-making with patients: a mixed methods implementation study. Implement Sci. 2014;9:144. PubMed PMID: 25280742. Pubmed Central PMCID: 4201673.

14.Akl EA, Oxman AD, Herrin J, Vist GE, Terrenato I, Sperati F, et al. Framing of health information messages. The Cochrane database of systematic reviews. 2011 (12):CD006777. PubMed PMID: 22161408.

15. Group GIW, Group GPW. Guidance for Developing Patient-Oriented Guideline Implementation Tools. Guidelines International Network, 2015 in progress. Report No.

16.van der Weijden T, Pieterse AH, Koelewijn-van Loon MS, Knaapen L, Legare F, Boivin A, et al. How can clinical practice guidelines be adapted to facilitate shared decision making? A qualitative keyinformant study. BMJ quality \& safety. 2013 Oct;22(10):855-63. PubMed PMID: 23748154.

17. Gagliardi AR, Brouwers MC, Palda VA, Lemieux-Charles L, Grimshaw JM. How can we improve guideline use? A conceptual framework of implementability. Implement Sci. 2011;6:26. PubMed PMID: 21426574. Pubmed Central PMCID: 3072935. 
18.van der Weijden T, Legare F, Boivin A, Burgers JS, van Veenendaal H, Stiggelbout AM, et al. How to integrate individual patient values and preferences in clinical practice guidelines? A research protocol. Implement Sci. 2010;5:10. PubMed PMID: 20205815. Pubmed Central PMCID: 2824684.

19.Legare F, Stacey D, Turcotte S, Cossi MJ, Kryworuchko J, Graham ID, et al. Interventions for improving the adoption of shared decision making by healthcare professionals. The Cochrane database of systematic reviews. 2014;9:CD006732. PubMed PMID: 25222632.

20. Blencowe NS, Brown JM, Cook JA, Metcalfe C, Morton DG, Nicholl J, et al. Interventions in randomised controlled trials in surgery: issues to consider during trial design. Trials. 2015;16:392. PubMed PMID: 26337522. Pubmed Central PMCID: 4558964.

21.Ryan R, Santesso N, Lowe D, Hill S, Grimshaw J, Prictor M, et al. Interventions to improve safe and effective medicines use by consumers: an overview of systematic reviews. 2014.

22. Elwyn G, Frosch D, Volandes AE, Edwards A, Montori VM. Investing in deliberation: a definition and classification of decision support interventions for people facing difficult health decisions. Med Decis Making. 2010 Nov-Dec;30(6):701-11. PubMed PMID: 21088131.

23. Stacey D, Hill S. The Knowledge to Action Cycle. Selecting KT interventions: Patient-direct and Patient-mediated KT Interventions. ?: ?; 2013.

24.Carman KL, Dardess P, Maurer M, Sofaer S, Adams K, Bechtel C, et al. Patient and family engagement: a framework for understanding the elements and developing interventions and policies. Health affairs. 2013 Feb;32(2):223-31. PubMed PMID: 23381514.

25. Liira H, Saarelma O, Callaghan M, Harbour R, Jousimaa J, Kunnamo I, et al. Patients, health information, and guidelines: A focus-group study. Scandinavian journal of primary health care. 2015;33(3):212-9. PubMed PMID: 26205344.

26. Taylor SJC, Pinnock H, Epiphaniou E, Pearce G, Parke HL, Schwappach A, et al. A rapid synthesis of the evidence on interventions supporting self-management. A rapid synthesis of the evidence on interventions supporting self-management for people with long-term conditions: PRISMS - Practical systematic Review of Self-Management Support for long-term conditions. Health Services and Delivery Research. Southampton (UK)2014.

27. Colquhoun H, Leeman J, Michie S, Lokker C, Bragge P, Hempel S, et al. Towards a common terminology: a simplified framework of interventions to promote and integrate evidence into health practices, systems, and policies. Implement Sci. 2014;9:51. PubMed PMID: 24885553. Pubmed Central PMCID: 4021969.

28. Elwyn G, Quinlan C, Mulley A, Agoritsas T, Vandvik PO, Guyatt G. Trustworthy guidelines - excellent; customized care tools - even better. BMC medicine. 2015;13:199. PubMed PMID: 26324120. Pubmed Central PMCID: 4556022.

29. Cox CE, White DB, Abernethy AP. A universal decision support system. Addressing the decisionmaking needs of patients, families, and clinicians in the setting of critical illness. American journal of respiratory and critical care medicine. 2014 Aug 15;190(4):366-73. PubMed PMID: 25019639. Pubmed Central PMCID: 4214132.

30. Rhodes CA. User involvement in health and social care education: a concept analysis. Nurse education today. 2012 Feb;32(2):185-9. PubMed PMID: 22153057.

31.Zuiderent-Jerak T, Jerak-Zuiderent S, van de Bovenkamp HM, Swan TS, Hakkaart-van Roijen L, Brouwer W, et al. Variatie in richtlijnen; wat is het probleem? The Hague, The Netherlands: Regieraad Kwaliteit van Zorg, 2011 April 2011. Report No.

32. Boivin A, Green J, van der Meulen J, Legare F, Nolte E. Why consider patients' preferences? A discourse analysis of clinical practice guideline developers. Medical care. 2009 Aug;47(8):908-15. PubMed PMID: 19543120.

The Dutch Chaos Case: a scoping review of knowledge transfer and decision support tools in the Netherlands, Dunja Dreesens - submitted 


\section{Annex D - Tool types and definitions used at the start of the meeting}

In a Delphi study in the Netherlands an expert panel reached consensus on the selection and definitions of a core set of knowledge and decision support tools primarily used in the care process by patient and / or professional (in or outside consultation).

In the grey rows the tool types that were included during the invitational.

\begin{tabular}{|c|c|c|}
\hline $\begin{array}{l}\text { Type of } \\
\text { knowledge tool }\end{array}$ & Definition & \\
\hline $\begin{array}{l}\text { Clinical practice } \\
\text { guideline }\end{array}$ & $\begin{array}{l}\text { Recommendations for a specific (health) care issue based on 1) a } \\
\text { systematic summary of scientific research, 2) considerations of the } \\
\text { advantages and disadvantages of various care options and 3) the } \\
\text { knowledge and experiences of patients and providers; supports decision- } \\
\text { making in the care process and is aimed at safeguarding and improving } \\
\text { the quality of life and care }\end{array}$ & $\begin{array}{l}\text { Included (as } \\
\text { patient version } \\
\text { of guideline) } \\
\text { (1) }\end{array}$ \\
\hline $\begin{array}{l}\text { Decision tree/flow } \\
\text { chart }\end{array}$ & $\begin{array}{l}\text { Logically structured visualization of possibilities in a (health) care issue } \\
\text { with associated outcomes, opportunities, risks and decision points; offers } \\
\text { care providers and patients insight into the relevant care policies and } \\
\text { supports decision making }\end{array}$ & Included (2) \\
\hline $\begin{array}{l}\text { Summary (of } \\
\text { guideline) }\end{array}$ & $\begin{array}{l}\text { Concise overview of the guideline providing main conclusions and } \\
\text { recommendations in clear and simple language; can be applied in practice } \\
\text { independently from the guideline; intended for both care providers and } \\
\text { patients }\end{array}$ & excluded \\
\hline Protocol & $\begin{array}{l}\text { Instruction derived from a guideline, indicating how care providers should } \\
\text { act in daily practice, within the restraints of specific local circumstances }\end{array}$ & excluded \\
\hline $\begin{array}{l}\text { Patient decision } \\
\text { aid (PDA) /support } \\
\text { tool }\end{array}$ & $\begin{array}{l}\text { Supporting information and answers to frequently asked questions for } \\
\text { patients when choosing, with their care providers, from different options - } \\
\text { including the option to forgo care - in areas such as diagnostics, } \\
\text { treatment, screening, counselling and aftercare; discusses the possible } \\
\text { outcomes and effects of each option - desirable or otherwise - their } \\
\text { likelihood to occur; helps patients weigh up their options based on their } \\
\text { own values, standards and personal circumstances }\end{array}$ & $\begin{array}{l}\text { Included - and } \\
\text { split into two: } \\
\text { encounter PDA } \\
\text { (3) and } \\
\text { independent } \\
\text { PDA (4) }\end{array}$ \\
\hline $\begin{array}{l}\text { Patient /client } \\
\text { information }\end{array}$ & $\begin{array}{l}\text { Explanation of a specific condition or (health) care issue based on a } \\
\text { guideline; made available to patients and their next of kin; provides } \\
\text { information on available care choices and the care they can expect from } \\
\text { the care process }\end{array}$ & Included (5) \\
\hline Viewpoint & $\begin{array}{l}\text { Rules of conduct for a topical and/or delicate (health) care issue; drawn } \\
\text { up on a fast-track, ad hoc basis by a professional or scientific association } \\
\text { in collaboration with patients; provides guidance for care providers and } \\
\text { patients when a guideline is not yet available }\end{array}$ & excluded \\
\hline Care pathway & $\begin{array}{l}\text { Guideline-based description of the shared decision-making in the care } \\
\text { setting regarding the (health) care provided to a patient with a specific } \\
\text { care need; intended for care providers; aimed at delivering optimal care, } \\
\text { tailored to the needs of the specific patient }\end{array}$ & excluded \\
\hline Quality standard* & $\begin{array}{l}\text { Description of good care for a specific health-related theme in } \\
\text { accordance with the Dutch National Health Care Institute's assessment } \\
\text { framework; helps to improve and ensure quality of life and care; intended } \\
\text { for guideline developers }\end{array}$ & excluded \\
\hline Care standard* & $\begin{array}{l}\text { Description of the organization of multidisciplinary care - including } \\
\text { prevention - for a particular care issue; based on scientifically } \\
\text { substantiated topical insights; may indicate tasks and be drafted from the } \\
\text { perspective of the patient; covers in particular support for self- } \\
\text { management; may include performance indicators }\end{array}$ & excluded \\
\hline Care module* & $\begin{array}{l}\text { Description of an item of care relevant to several care issues; can be part } \\
\text { of multiple care standards; brings into line non-disease-specific care in } \\
\text { relevant care standards }\end{array}$ & excluded \\
\hline
\end{tabular}

* Unsure whether these tools are known, and/or used in other countries than the Netherlands 


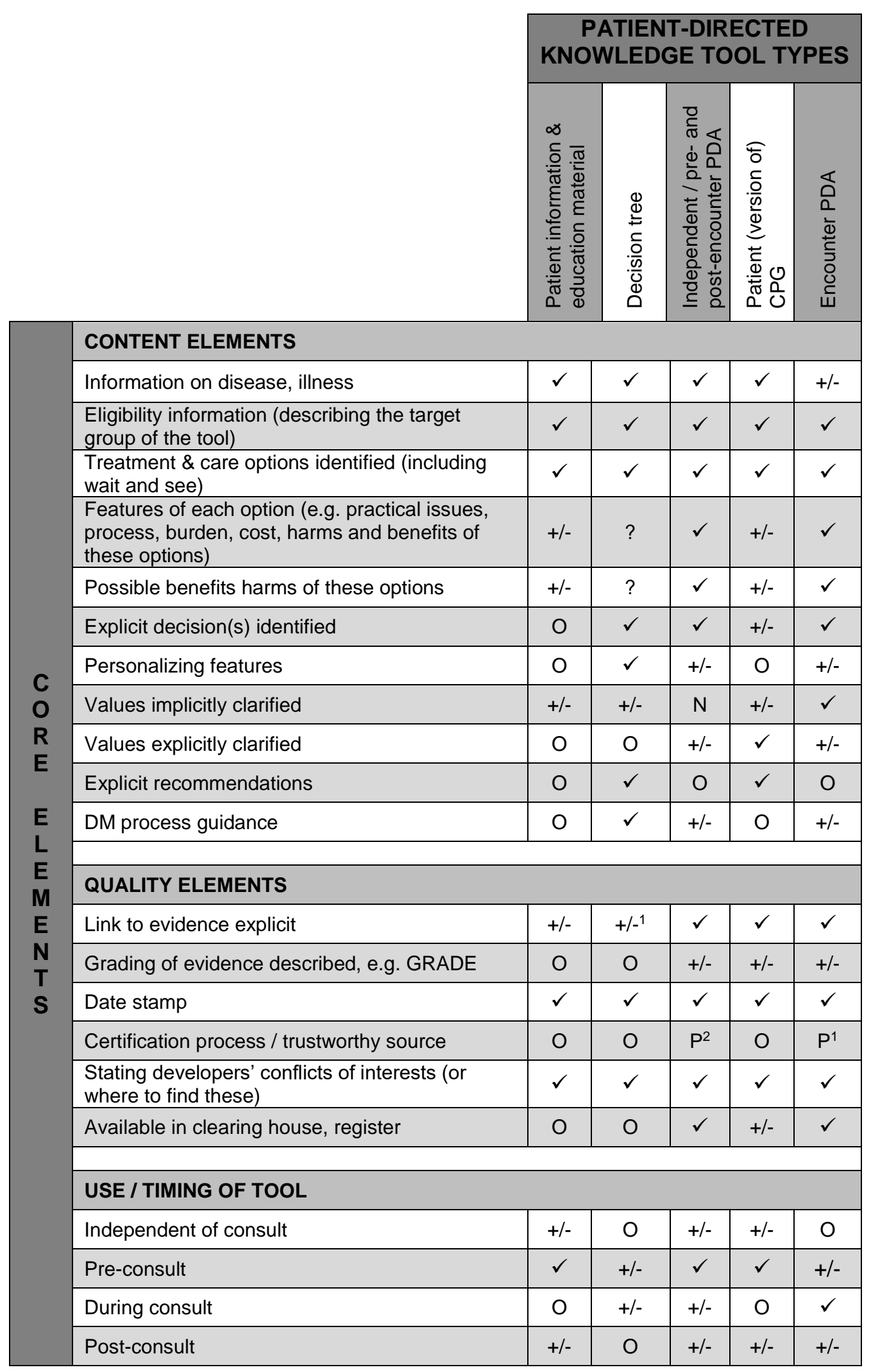




Legend
\begin{tabular}{|l|l|}
\hline$\checkmark$ & Necessary \\
\hline$+/-$ & Possibly \\
\hline$O$ & Not typical \\
\hline P & Present \\
\hline$?$ & Not known (yet) \\
\hline
\end{tabular}

${ }^{1} \mathrm{P}$ (in Netherlands only)

$2 \mathrm{P}$ (in USA only)

Abbreviations:

- CPG: Clinical practice guideline

- PDA: patient decision aid

- DM: decision making

- GRADE: Grading of Recommendations Assessment, Development and Evaluation 